\title{
Textural and structural modifications of saponite from Cerro del Aguila by acid treatment
}

\author{
M. SUÁREZ BARRIOS ${ }^{1} *$, C. DE SANTIAGO BUEY ${ }^{2}$, E. GARCÍA ROMERO \\ AND J. M. MARTÍN POZAS ${ }^{1}$ \\ ${ }^{1}$ Area de Cristalografía y Mineralogía, Departamento de Geología, Facultad de Ciencias, Universidad de Salamanca, \\ Plaza de la Merced S/N, E-37008-Salamanca, Spain, and ${ }^{2}$ Departamento de Cristalografía y Mineralogía, Facultad de \\ Geología, Universidad Complutense de Madrid, Ciudad Universitaria, Madrid, Spain
}

(Received 16 August 2000; revised 29 January 2001)

\begin{abstract}
The physicochemical properties of clays can be modified by acid treatment with inorganic acids. This treatment is usually referred to as 'acid activation', because it increases the specific surface area and the number of active sites of the solids. In the present study, the acid activation of saponite from Cerro del Aguila (Madrid, Spain) with $\mathrm{HCl}$ solutions was measured. Illite, quartz and small amounts of feldspar were found as impurities in the raw saponite.

Acid treatments were carried out with different concentrations of $\mathrm{HCl}$ solutions. The samples obtained were characterized by mineralogical and chemical analyses, XRD, FT-IR spectroscopy, $\mathrm{N}_{2}$ adsorption-desorption isotherms and TEM. The acid attack, under the conditions employed, produced a progressive destruction of the structure of saponite by partial dissolution of the octahedral $\mathrm{Mg}$ (II) cations. Amorphous silica coming from the tetrahedral sheet of saponite was generated. The specific surface area of the most intensely treated sample $(2.5 \%$ for $24 \mathrm{~h})$ was doubled with respect to that of natural saponite. This increase in the surface area is due to the increase in both the external and internal surface areas.
\end{abstract}

KEYWORDS: bentonite, saponite, acid activation, transmission electron microscopy, Spain

The acid treatment of clay minerals is usually referred to as 'acid activation', because it increases the specific surface area and the number of active sites of the solids. This treatment modifies the surfaces of clays by disaggregation of particles, possible elimination of mineral impurities and removal of metal-exchange cations. The common commercial use of acid-treated bentonite is the bleaching or decolouration of oils (Siddiqui, 1968; Srasra et al., 1989) and in general in the fields of adsorption and catalysis (Fahn \& Fenderl, 1983; Mokaya \& Jones, 1995).

There are few references in the literature to saponite, from the acid activation point of view

* E-mail:msuarez@gugu.usal.es

DOI: $10.1180 / 0009855013640003$
(Vicente et al., 1994, 1996; Kooli \& Jones 1997; Prieto et al., 1999), compared with montmorillonite. Nevertheless, saponite is more easily soluble in an acid medium (because of the composition of its octahedral sheet) and products of high added value can be obtained using a smaller amount of acid, in a shorter period of time and at lower treatment temperatures.

In order to improve the industrial application properties of this saponite, and the products that can be obtained after acid treatment, it is necessary to characterize the physicochemical properties of the material (composition, particle size, porosity, presence of crystalline defects in the structure, impurities, etc.) which depend on the mineralformation process. In this study we performed a physicochemical characterization of saponite from 
Cerro del Aguila and of the samples resulting from attack by hydrochloric acid, using different concentrations and different treatment times.

\section{MATERIALS AND METHODS}

The bentonite studied (SmMa) from Cerro del Aguila (Provinces of Madrid and Toledo, Spain) is composed mainly of trioctahedral smectite. The impurities detected by X-ray diffraction (XRD) are illite, quartz and alkali and plagioclase feldspars (Santiago Buey et al., 1996).

A $5 \mathrm{~g}$ sample of the clay was treated during mechanical stirring with $150 \mathrm{ml}$ of $0.62,1.25$ and 2.5 wt. $\%$ solutions of $\mathrm{HCl}$, at $25^{\circ} \mathrm{C}$ for 6 and $24 \mathrm{~h}$. The six resulting solids were washed until no chloride anions could be detected.

The mineralogical study was performed by XRD, using a Siemens D-500 XRD diffractometer with a $\mathrm{Cu}$ anticathode and a graphite monochromator.

The elemental analysis was performed by Activation Laboratories Ltd., Ancaster, Ontario, Canada, using Inductively Coupled Plasma Spectroscopy (ICPS) and Atomic Absorption Spectroscopy (AAS).

Nitrogen adsorption-desoption isotherms of the original and treated samples were obtained at $77 \mathrm{~K}$ using a Micromeritics ASAP 2010 analyser after outgassing the samples at $110^{\circ} \mathrm{C}$ for $4 \mathrm{~h}$ with a residual pressure of $10^{-5} \mathrm{~mm} \mathrm{Hg}$. Calculation of the BET surface and of the internal and external surfaces (equivalent to micropore and mesopore surfaces) was performed using a computer program supplied with the equipment (ASAP 2010 v. 3.0).

Transmision electron microscopy (TEM) studies were performed on specimens that retained their original textures. Oriented sections were made, according to the method proposed by Tessier (1984). This method shows evidence of swelling phases by penetrating hydrated interlayers such as those present in smectites (Tessier \& Pedro, 1987). The TEM observations were performed in a JEM 2000FX operated at $200 \mathrm{kV}$ and equipped with a Link AN10000 X-ray energy dispersive detector. The sample subjected to the mildest treatment, i.e. 0.62 wt. $\% \mathrm{HCl}$ for $6 \mathrm{~h}(0.62 \%-6 \mathrm{~h})$ and an untreated sample were studied by TEM.

\section{RESULTS AND DISCUSSION}

The chemical compositions of the natural saponite (SmMa sample) and solids resulting from the different acid treatment are given in Table 1. The solids obtained after acid treatment (both the $6 \mathrm{~h}$ series and $24 \mathrm{~h}$ series) showed a progressive decrease in their $\mathrm{MgO}$ content and an enrichment in $\mathrm{SiO}_{2}$. The partial dissolution of the octahedral sheet removed some of the $\mathrm{Mg}$ and $\mathrm{Fe}$, thereby increasing the percentage of $\mathrm{Si}$ in the remaining composition. The $\mathrm{Al}$ and $\mathrm{Fe}$ octahedral cations were not removed under the conditions employed. It is possible that these elements are located in plagioclase $(\mathrm{Al})$ and in the octahedral sites of the layers of illitic composition, which are not dissolved. In the more intensely treated sample $(2.5 \% \mathrm{HCl}-24 \mathrm{~h}), 88 \%$ of $\mathrm{MgO}$ was removed. These results agree with those of Vicente Rodríguez et al. (1994) who found that $\mathrm{Mg}$ is more easily dissolved than $\mathrm{Al}$ and $\mathrm{Fe}$ when treating saponite rich in $\mathrm{Fe}$ with $\mathrm{HCl}$ solutions. The $\mathrm{Ca}$ content also decreases even when the treatment is very mild because this element is the principal exchangeable cation. Only $0.2 \%$ of $\mathrm{CaO}$ remains in the treated samples, and this is probably present in the plagioclase impurity.

TABLE 1. Chemical composition of the natural saponite and solids resulting from different acid treatments (in oxide form).

\begin{tabular}{llllrrrr}
\hline Sample & $\mathrm{SiO}_{2}$ & $\mathrm{Al}_{2} \mathrm{O}_{3}$ & $\mathrm{Fe}_{2} \mathrm{O}_{3}$ & $\mathrm{MgO}$ & $\mathrm{CaO}$ & $\mathrm{Na}_{2} \mathrm{O}$ & $\mathrm{K}_{2} \mathrm{O}$ \\
\hline SmMa & 59.73 & 13.5 & 4.65 & 17.15 & 0.90 & 0.64 & 2.62 \\
$0.62 \%-6 \mathrm{~h}$ & 64.86 & 13.84 & 4.93 & 13.01 & 0.22 & 0.63 & 2.82 \\
$0.62 \%-24 \mathrm{~h}$ & 66.43 & 13.79 & 5.03 & 10.68 & 0.20 & 0.65 & 2.93 \\
$1.25 \%-6 \mathrm{~h}$ & 65.9 & 14.11 & 5.07 & 10.92 & 0.20 & 0.68 & 2.96 \\
$1.25 \%-24 \mathrm{~h}$ & 68.8 & 13.20 & 4.80 & 8.77 & 0.21 & 0.65 & 2.86 \\
$2.5 \%-6 \mathrm{~h}$ & 67.06 & 13.88 & 5.00 & 10.17 & 0.19 & 0.68 & 2.88 \\
$2.5 \%-24 \mathrm{~h}$ & 71.4 & 13.84 & 4.78 & 2.27 & 0.22 & 0.74 & 3.09 \\
\hline
\end{tabular}




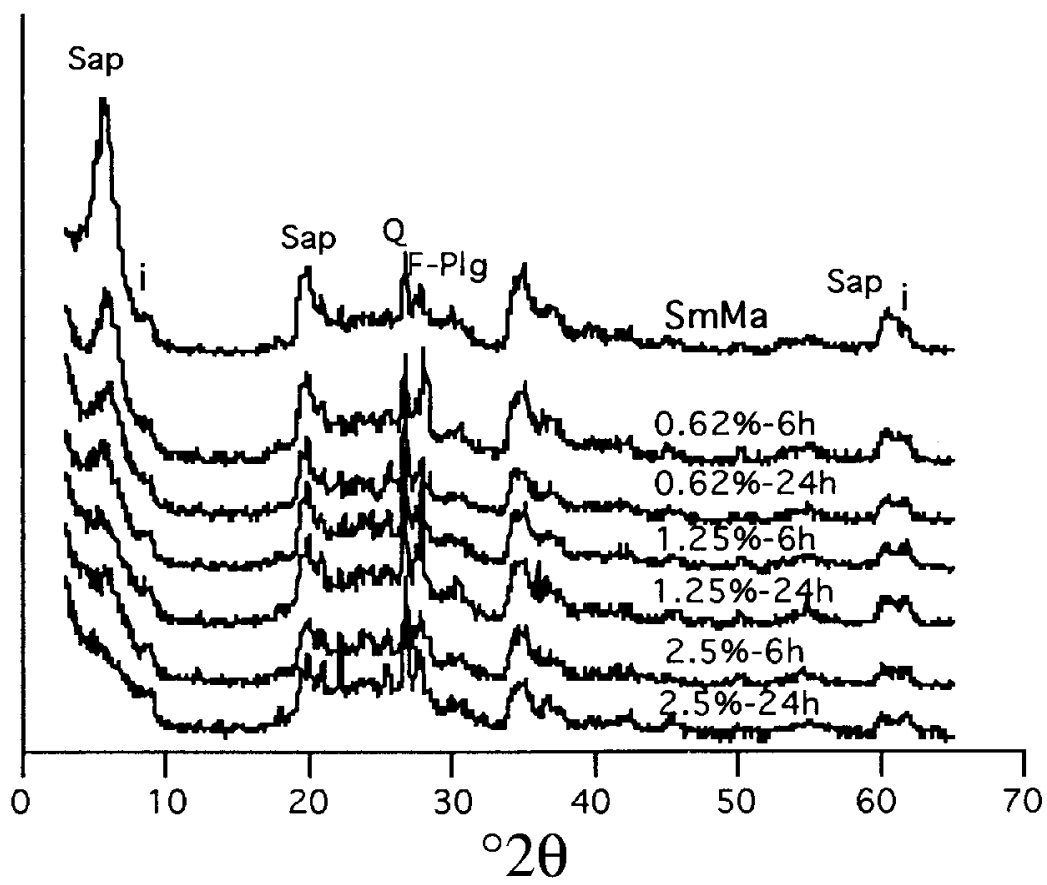

FIG. 1. XRD traces of natural the saponite and of the treated samples (Sap: saponite, I: illite, Q: quartz, F-Plg: plagioclase feldspar.

The XRD traces of the treated samples are given in Fig. 1, in which a trace for natural saponite is included for comparative purposes. When the treatment time and the concentration of the acid solutions were increased, the intensity of the 001 reflection decreased, and the crystallinity of the saponite also decreased, as can be seen by the broadening of the peak at $14 \AA$. At the same time, a broad band at $\sim 15-30^{\circ} 2 \theta$, corresponding to the amorphous silica, appeared and increased in intensity as the concentration of the acid solutions increased. Silica comes from the tetrahedral sheet by partial destruction of the structure of the clay due to dissolution of the octahedral sheet. These results agree with those of Vicente Rodríguez et al. (1994) when studying the acid activation of griffithite and those of Suquet et al. (1992) when treating Llano vermiculite.

The destruction of the structure by partial dissolution of the octahedral sheet is deduced from the disappearance of the 001 reflection and from the diminution of the intensity of the 060 reflection at $1.53 \AA$. Delamination was observed and the $h k 0$ reflection was preserved in the XRD traces, although with less intensity. The relative concentration of insoluble impurities (mainly illite, quartz and feldspar) was observed. In Fig. 1 it is possible to see the diminution of the intensity of the 060 reflections of saponite (at $1.53 \AA$ ) and the increase of the intensity of the 060 reflections of dioctahedral illite (at $1.49 \AA$ ) in the treated samples, with respect to the natural sample, due to the destruction of saponite and relative concentration of illite.

TABLE 2. BET surface, external surface and internal surface of the natural and treated samples.

\begin{tabular}{lccc}
\hline Sample & $\begin{array}{c}\mathrm{S}_{\mathrm{BET}} \\
\left(\mathrm{m}^{2} \mathrm{~g}^{-1}\right)\end{array}$ & $\begin{array}{c}\mathrm{S}_{\mathrm{EXT}} \\
\left(\mathrm{m}^{2} \mathrm{~g}^{-1}\right)\end{array}$ & $\begin{array}{c}\mathrm{S}_{\mathrm{INT}} \\
\left(\mathrm{m}^{2} \mathrm{~g}^{-1}\right)\end{array}$ \\
\hline SmMa & 139 & 90 & 49 \\
$0.62 \%-6 \mathrm{~h}$ & 209 & 140 & 61 \\
$0.62 \%-24 \mathrm{~h}$ & 224 & 155 & 69 \\
$1.25 \%-6 \mathrm{~h}$ & 224 & 158 & 66 \\
$1.25 \%-24 \mathrm{~h}$ & 237 & 158 & 79 \\
$2.5 \%-6 \mathrm{~h}$ & 239 & 156 & 83 \\
$2.5 \%-24 \mathrm{~h}$ & 281 & 168 & 113 \\
& & & \\
\hline
\end{tabular}


The specific surface areas of the solids were calculated from the isotherms, using the BET method. The results obtained are given in Table 2 . Natural saponite has a high surface area $\left(139 \mathrm{~m}^{2} \mathrm{~g}^{-1}\right)$. The acid treatment of saponite, under the conditions used, produces an increase in the specific surface area of up to $102 \%$ in the most intensely treated sample $(2.5 \%-24 \mathrm{~h})$. This increase is due to the increase in both the external and internal surface areas (equivalent to meso- and micropore suface area). The external surface increases both with the increase in the concentration and with the increase in the time of treatment, reaching a maximum of $168 \mathrm{~m}^{2} \mathrm{~g}^{-1}$ for the most strongly attacked sample (2.5\%-24 h). On the other hand, the more aggresive the treatment, the greater the increase in the internal surface area due to the creation of microporosity by partial dissolution of the octahedral sheet.

The TEM micrographs revealed the coexistence of pure smectite (saponite), pure illite and

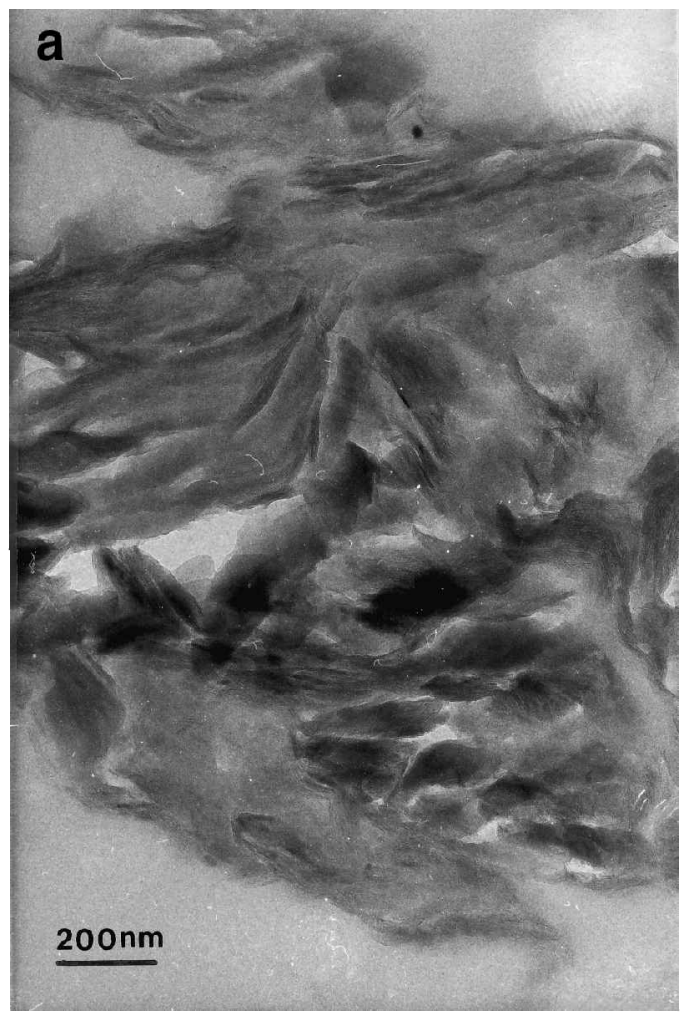

interstratified illite-smectite in a natural sample. Saponite occurs extensively surrounding illite particles. Saponite particles showed anastomosing and imperfect $14 \AA$ lattice fringe images with typical changes in image contrast along the layers and a high density of dislocations (Santiago Buey et al., 1998). These structural faults can obstruct the protons' path and impede the dissolution of the octahedral sheet. Very small particles of saponite were also found in the natural sample and they were easily dissolved by the acid treatment because of their large surface area.

Observation of the sample subjected to the mildest treatment $(0.62 \%-6 \mathrm{~h})$ allowed us to confirm that the general texture did not vary. The typical grouping of particles characteristic of smectites (Fig. 2a) was observed. Detailed study of these particles (Fig. 2b) revealed the discontinuity of the phyllosilicate layers. Small layers were identified, grouped in parallel, but without lateral continuity. The disarticulation of the particles due

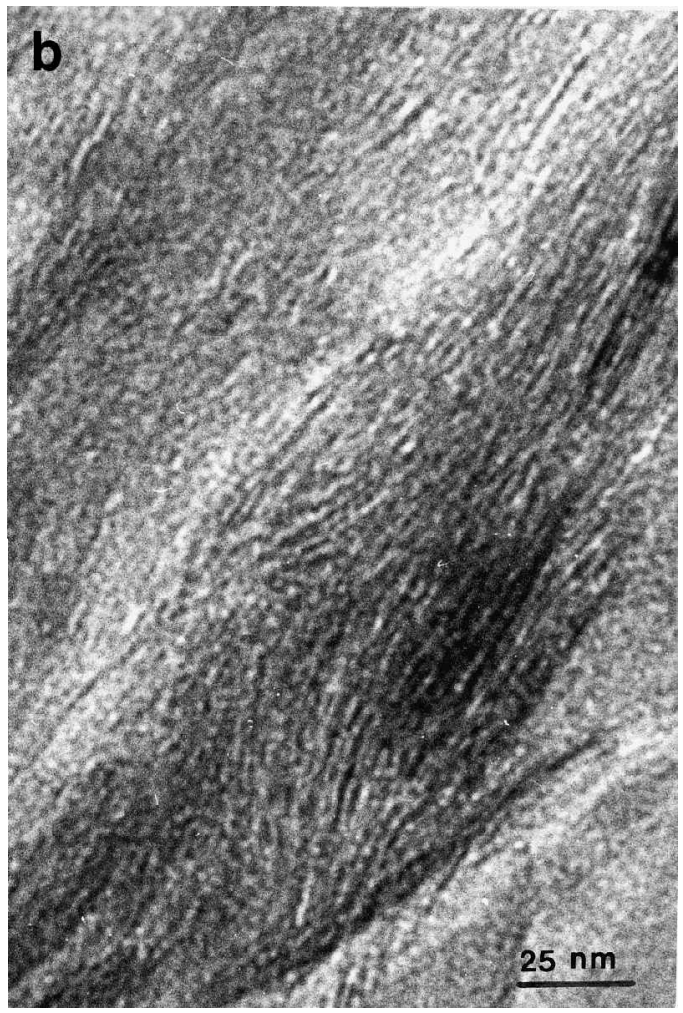

FIG. 2. (a) TEM micrograph of a general view of the $0.62 \%-6 \mathrm{~h}$ sample. (b) TEM micrograph of layer arrangement in the $0.62 \%-6 \mathrm{~h}$ sample. 
to acid attack gave rise to the formation of interlayer thicknesses of resin of up to $30 \AA$, with the appearance of very open layers together with other remains of non-attacked saponite which maintained the characteristic smectite spacing (14 $\AA$ ) under this sample treatment. Amorphous zones were also observed which must correspond to the silica identified by XRD.

Observation of the ultrafine cuts of the $0.6 \%-6 \mathrm{~h}$ sample confirmed the data obtained for analysis of the $\mathrm{N}_{2}$ adsorption isotherm, since delamination and fragmentation of the particles would give rise to a large increase, mainly in the external surface area.

Kaviratna \& Pinnavaia (1994) studied the attack mechanism in the hydrolysis of two trioctahedral phyllosilicates, posing the possibility of "a gallery access" or of an "edge attack" and found that the main mechanism in the dissolution of these minerals to be the latter. In the present case, taking into account the observations made using TEM, we think that there may be "gallery access" and not just "edge attack" since with the milder treatment a large decrease in particle size is noted. It must be taken into account that, with this milder treatment $(0.62 \%$ $\mathrm{HCl}-6 \mathrm{~h}$ ), the exchange cations were exchanged for protons, and the resulting delamination gave rise to an increase in the surface area and hence to accessibility of the protons.

\section{CONCLUSIONS}

Acid attack produces a progressive destruction of the structure of saponite from Cerro del Aguila by delamination of the particles and by partial dissolution of the octahedral Mg. Although the conditions employed in the leaching are very mild, most of the octahedral sheet of the saponite is dissolved. The feldspars and illitic component in the sample are not dissolved and are responsible for the $\mathrm{Al}_{2} \mathrm{O}_{3}$ and $\mathrm{Fe}_{2} \mathrm{O}_{3}$ which remain in the sample. Amorphous silica coming from the tetrahedral sheet of saponite is generated.

A large increase in the surface area of the solids is observed. The diminution of the size of the particles and the increase of the micro- and mesoporosities together with particle disaggregation and free silica generation contribute to the increase in surface area.

The acid treatment process occurs not only from the edge towards the inside of the particles but also through "access galleries" that fragment the particles.

\section{ACKNOWLEDGMENTS}

The authors are grateful for financial support from CICYT (MAT96-0643 Project) and to Barbara Knowles for translating the manuscript. We would like to thank Dr Bergaya and an anonymous referee for their careful review and interesting comments.

\section{REFERENCES}

Fahn R. \& Fenderl K. (1983) Reaction products of organic dye molecules with acid treated montmorillonite. Clay Miner. 18, 447-458.

Kaviratna H. \& Pinnavaia T.J. (1994) Acid hydrolysis of octahedral $\mathrm{Mg}^{2+}$ sites in 2:1 layered silicates: An assessment of edge attack and gallery access mechanisms. Clays Clay Miner. 42, 717-723.

Kooli F. \& Jones W. (1997) Characterization and catalytic properties of a saponite clay modified by acid activation. Clay Miner. 33, 633-643.

Mokaya R. \& Jones W. (1995) Pillared clays and pillared acid-activated clays: A comparative study of physical, acidic and catalytic propierties. J. Catal. 153, 76-85.

Prieto O., Vicente M.A. and Bañares-Muñoz M.A. (1999) Study of porous solids obtained by acid treatment of a high surface area saponite. J. Porous. Mater. 6, 335-344.

Santiago Buey de C., Suárez Barrios M., García Romero E., Doval Montoya M. \& Domínguez Díaz M.C. (1996) Study of the bentonites from the 'Cerro del Aguila' (Toledo, Spain). Advances in Clay Minerals. Proc. Spanish-Italian Meeting on Clay Minerals, Granada (M. Ortega-Huertas, A. López-Galindo \& I. Palomo-Delgado, editors).

Santiago Buey de C., Suárez Barrios M., García Romero E., Domínguez Díaz M.C. \& Doval Montoya M. (1998) Electron microscopic study of the illitesmectite transformation in the bentonites from Cerro del Aguila (Toledo, Spain). Clay Miner. 33, 501-510.

Siddiqui M.K.H. (1968) Bleaching Earths. Pergamon Press, Oxford.

Srasra E., Bergaya F., Vandamme H. \& Ariguib N.K. (1989) Surface properties of an activated bentonite. Decolorization of rape-seed oils. Appl. Clay Sci. 4, 411-421.

Suquet H., Chevalier S., Marcilly C. \& Barthomeuf D. (1992) Preparation of porous materials by chemical activation of the Llano vermiculite. Clay Miner. 26, 49-60.

Tessier D. (1984) Etude de l'organisation des matériaux argileux. Hydratation, gonflement et structuration au cours de la dessiccation et de la réhumectation. Thése de Docteur en Sciences de l'Univ. Paris VII.

Tessier D. \& Pedro G. (1987) Mineralogical characterization of 2:1 clays in soils: Importance of the clay 
texture. Proc. Int. Clay Conf. Denver, 78-84.

Vicente Rodríguez M.A., Suárez Barrios M., López González J.D. \& Bañares Muñoz M.A. (1994) Acid activation of a ferrous saponite (griffithite): Physicochemical characterization and surface area of the products obtained. Clays Clay Miner. 42, 724-730.
Vicente Rodríguez M.A., Suárez Barrios M., Bañares Muñoz M.A. \& López Gonzalez J.D. (1996) Comparative FT-IR study of the removal of octahedral cations and structural modifications during acid treatment of several silicates. Spectrochim. Acta A, 52, 1685-1694. 